\title{
Women \& Girls on the Autism Spectrum: A Profile
}

\author{
Wenn B. Lawson*
}

ACRC, The University of Queensland, C/O PO Box 5033, Warrnambool, Vic. 3280, Australia

\begin{abstract}
Being female and autistic is poorly understood, but is autism really 'rare' in females? Historically, autism has been associated with traditionally masculine features and stereotypes of behaviour, with some believing autism only occurred in males [1]. This leads scientific enquiry to the critical question of whether there are more males living with autism or, conversely, do females on the autistic spectrum present differently to males and, therefore, are at risk of remaining undiagnosed?
\end{abstract}

Keywords: Autism, Females, Presentation, Diagnosis, Gender.

Traditionally, over the last decade, only 1 female to every 3 or 4 males has received a diagnosis of autism. Often, females who are readily diagnosed as autistic have tended toward the severe end of the spectrum, being 'classically' autistic or having 'Kanner' type autism with intellectual disability; or Autism level 3 [13]. Even though Hans Asperger's work eventually opened doors to a deepening awareness of autism as a spectrum, his original work was only with males [4].

Essentially, the question is, are there more males living with autism or do females on the autistic spectrum present differently to males? What we are beginning to appreciate is the profile of autism's impact upon females is often different to that seen in males (e.g. [5-8].

Sex and gender, both in biological sex and in gender identity, are both concepts which are expressed along a spectrum. However, this spectrum isn't linear, but circular. This understanding, and complexity, is often over looked when it comes to autism. We have been taught to believe chromosomes equal either $\mathrm{XX}$ for females or $X Y$ for males. However, reality is significantly more complex (http://www.who.int/ genomics/gender/en/index1.html).

Females differ in how they choose to express their gender across different contexts and domains such as physical presentation, communicative style and behavior. This expression can vary between being ultra-feminine, to the point of expressing almost exaggerated femaleness, to almost resenting any hint of stereotypical femininity where individuals live as tomboys, even if they have XX chromosomes. Many also lie between these two extremes. Research argues

*Address correspondence to this author at the ACRC, Long Pocket Campus, The University of Queensland, PO Box 5033, Warrnambool, Vic. 3280, Australia; E-mail: wenbe@bigpond.com gender identity is not so much about chromosomes, as it is about gender identity in the brain, but being female and having different chromosomes to males and different neurobiology than males will impact the profile of autism in females. However, does this mean autism presents differently to that seen in males, but may also vary according to where a female 'sits' on the gender spectrum $[9,10]$ ?

Until recently the idea of females having a different profile of autism characteristics received very little attention [11]. However, according to Lai, et al. as cited in Moyse, et al. p. 187 [12]:

"girls who appear to be cognitively able or appear to have better communication skills may have been under-diagnosed".

As well as being underdiagnosed or miss-diagnosed with a mental health issue (Social Phobia; Depression; Borderline Personality Disorder and so on) the needs of females are being over looked and their difficulties aren't being understood [11].

Yet, despite this there is an increasing amount of literature that discusses the differences in females compared to males [12-19]. However, this is failing to translate into practice. Although changing long-time attitudes for practitioners, takes time, this is an emerging need that warrants urgent attention. There are many misconceptions about how autism looks and this is getting in the way of seeing autism's different impact according to an individual's cis-gender, or otherwise.

In the past [20], details of the triad of impairments that affected those with autism, were richly described. The triad are listed as impairments of social interaction, impairments of social communication and impairments of social imagination [21]. However, the DSM-5 [2] has now combined the three domains into two: issues with 
social interaction and communication, as well as rigid behaviours domains. Possibly the DSM-5, that has drawn previous areas together as opposed to seeing them separated (previous versions, for example, listed Asperger's syndrome, Pervasive developmental disorder not otherwise specified (PDDNOS) and others, as separate conditions) may not have helped here. We are encouraged to view autism as a spectrum of difficulty but, when so much is pooled within the same pond, the danger is individual experiences can be over looked.

The other issue that may be contributing to misconceptions and reduced research attention on females and autism, is the theory that autism is influenced prenatally by testosterone leading to an extreme male brain (EMB) [22]. However, while this has predisposed many clinicians to think of autism only as a predominantly male disposition, it has also meant they have 'missed' the signs of autism in females and given, due to their bias of thinking autism is the result of an EMB, a mental health diagnosis instead. Research has shown that although there is some evidence that an EMB may impact autism in females, this is not the case for males in autism [23], and how it impacts on the female brain is still being debated.

For example, research by Carter et al. [6] shows female toddlers with autism being less socially competent than the boys. They are also better at nonverbal problem-solving than the boys.

"The findings revealed a statistically significant interaction between child sex and cognitive domain (verbal versus nonverbal) and child sex and the 5 Mullen Scales of Early Learning (Visual Reception, Fine Motor, Expressive Language, Receptive Language, and Gross Motor), indicating that girls and boys with $A S D$ show different cognitive and developmental profiles. Consistent with the expectation that boys would show more advanced development, boys evidenced stronger verbal and motor skills, particularly once differences in visual reception were covaried. Controlling for language level, girls evidenced significantly stronger skills in visual reception, or the nonverbal problemsolving domain. In addition, boys were described as having more advanced social functioning than girls...." P. 94.
As Bjorne [24] has pointed out:

"This all runs contrary to Baron-Cohen's idea of the male brain. Or, if you wish, the girls are more male than the boys. Given the fact that there are so very few studies addressing the cognitive profiles of autism from a gender perspective, it is important that the popular accounts are modified somewhat by more rigorous studies" Personal Communication.

If we look at the profile for many females, it seems they may not have the same communicative difficulties which typically trigger investigation into a potential diagnostic referral for males.

Females on the spectrum often experience Alexithymia. This means describing how they feel in social situations is hard and this may lead to an increase in their level of avoidance behaviours such as complaints of headaches, stomach aches or incidents of school refusal.

Autism is known to be a communication disorder. Some females appear to communicate well, having good eye contact and appropriate body language. Any discrepancy is likely put down to bad manners, lacking in discipline, or to the individual being strong willed or extremely shy. However, the very names we give to these behaviours should give us a hint that all is not well. We need to look beyond the behavior and ask certain questions. For example, is this behavior being used out of frustration due to not comprehending social norms; social expectations or processing social 'instincts'?

In cognitively challenged female individuals with a low IQ, autism operates at the severe end of the spectrum and is rarely questioned. But, in high functioning female individuals the double $X$ chromosome often gives them the feminine ability to mask their difficulties; copy behaviour in social settings that suggests they have an understanding and the true nature of the effort this takes is not seen. Therefore, when they appear not to understand or exhibit 'challenging behaviour,' they are thought of as being naughty, difficult or attention seeking. How do these females who society expects to be socially competent, cope in a world that expects them to be able to read body language, be friendly, sociable and happy in a group, understand the hidden curriculum (the unspoken rules of human interaction) and perform in society at the expected level, manage their daily lives? 
With answers also not reflecting a deeper social understanding, providing only a basic understanding, lacking in social comprehension, cognition and awareness as seen in their peers of typical developing age, it must take significant courage to simply attempt these interactions.

According to Attwood [5] girls fly under the radar as they learn to develop coping mechanisms, may have the ability to mask their social inadequacies through copying or mimicking those around them and often have passionate interests that are in line with typically developing females. They also are more able to learn and adhere to the social rules, learning acceptable behaviours for certain situations. This is effective in many situations, but often negatively affects the mental health of many girls, with an increase in anxiety due to the fear of rejection.

Girls become women and the expectations on women only increase with social expectations becoming highly complex.

Marshall [25] suggests the cultural expectations for females to participate in social communication such as chit-chat, small talk and gossip, is exhausting for those with high functioning autism. There is also a lack of social understanding which leads to confusion around things such as teasing, bullying and bitchiness often displayed by typically developing teens. Many high functioning female teens on the autism spectrum prefer to have their one, or select small group, of friends and become anxious in large group situations. Facial expressions of this group may not match their moods, often saying they are fine and looking happy on the outside but withdrawing internally. Females also tend to be more passive-aggressive in their behavior and use avoidance as a way of coping with the social demands placed upon them. They may also blame others, internalize their feelings or develop co-morbid conditions such as anxiety, depression, eating disorders or hyperactivity. As well as not being able to communicate with their peers, this group also struggles to understand the hierarchies within a societal structure and can get into trouble with adult's due to the way they speak with them.

Nichols, et al. [16] state girls on the spectrum present subtle differences in their behavior, when compared to their typical peers. For example, they are often able to answer questions about social situations, social communication and friendships but are slower to process the information. This would present great difficulty in understanding the conversations that go on between teenage girls within a group situation. Girls on the spectrum often struggle at school in the unstructured social play time. They may want to have friends but lack the 'innate' knowledge and skills to make and keep them [5]. Girls with autism are often excluded from play and the social play that happens at school, meaning they then miss out on the necessary skills to help shape their identity [12].

If having difficulty navigating the teenage years is hard for typically developing children how much more so is it for girls with high-functioning autism? [25, p.37]:

"Girls on the autism spectrum are more likely to come to the attention of health professional's due to difficulties with anxiety, depression, eating disorders, behavioural problems and/or social skills challenges. The presenting problem then becomes the 'diagnosis', with the larger picture and explanation for feeling "different" being missed".

Yaull-Smith [26] suggests girls with autism have a desire to please and fit in which makes them:

'hypersensitive to the environment,
vulnerable and easily manipulated, so they
are conditioned to conform to the social
norm but, as a result risk losing a sense of
identify- not least because social etiquette
and mores change and develop over time
and because a large part of conformity for
girls, in particular, is to please others' ( $p$
30).

As a result of being a girl on the spectrum and also having to contend with the societal pressures placed upon girls throughout the teenage years, their physical, mental and emotional health suffers. This road is often fraught with difficulty, misunderstanding and anxiety for the girl involved. It is important that for parents of girls on the spectrum they provide space, a place of safety within the home for the young person to feel they can truly be themselves and to always show respect and love towards them. A colleague of mine, in conversation, suggested that during this time, role play, meditation, yoga and understanding as well as teaching the understanding of social communication along with their feelings, could offer some support.

In many societies women are expected to marry, have a family, run a household and often some form of 
employment too. The DSM-5 [2] for the first time, includes sensory issues in the criteria housing autism. Women must face many challenging changes to their bodies, including menstruation, growing through puberty into the curves and shapely form of womanhood. The expectation is 'she will cope. It's natural, it's happened to all women since time began,' and so on. But, if an individual can't cope with these changes, the different smells, feelings and expectations, they may decide these won't happen to them. I have met females who decide not to grow up, so they continue to act like a child, stop eating to restrict their growth and employ any other behavior they believe will keep them from such a fate.

Then there's the issue of sexuality and keeping safe. For some female's this is a major issue. Some have little understanding of sexual etiquette, even if they have a normal IQ. The literal, black and white thinking processes in autism might mean if someone says: 'can you have sex with me' the person may reply 'yes' because they perceive the question to mean 'is it possible for you to have sex with me?' This is literal thinking that fails to negotiate the bigger picture.

An edited summary of some issues for females on the autism spectrum offered as, truth or myth.

Given to me by Katy Reid, a parent to two autistic daughters.

1 '...She's too social to be autistic' because she has friends or wants to have friends so she can't be autistic - MYTH

2. She looks at me when I speak to her, so she isn't autistic- MYTH. Girls may have good eye contact

3. Girls follow the rules - less likely to act out due to need to please others (Often True).

4. Girls will mimic others so they blend in but, their difficulties are often overlooked because of this (Often True).

5. Girls may find communicating their feelings unavailable to them and will become mute within the classroom - TRUE

6. Girls may not want to be the center of attention or have the spotlight on them - TRUE

7. Girls may have a love of technology, horses, animals, and friends - TRUE
8. Girls may live their lives through others and find personal autonomy allusive - TRUE

9. Girls live with severe anxiety (Often True)

10. Girls often have performance issues and won't settle for less than perfect (Often True)

11. Girls may be unable to stop certain behaviours such as having to twirl or spin. They may pick at their fingers, scrunch up their toes or face or have to twitch, all seemingly involuntary (Often True)

12. Girls may need to tune into their cues and follow strictly to know what comes next (Often True)

13. Girls may find it difficult to process lots of information at once. They need to do one thing at a time (Often True, unless connected to interest)

14. Girls need consistency, structure and continuity (Usually True)

15. Girls exhibit rigid behaviours and resist change TRUE

16. Routine is very important to girls and if it changes they need to have this visually explained or written down - TRUE.

17. Girls find body language and facial expressions difficult to read - TRUE.

18. Girls often have an inability to understand jokes or make jokes that others don't understand TRUE

19. Girls need to have others explain, in many different ways, what is happening and how things work (Often True)

20. LOTS and LOTS of questions about life are often repeated and answers may fail to make sense (Often True)

21. Girls show an inability to move on and let negatives go, they fixate on things and don't know how to process them or let it go (Often True)

In school Girls are often missed as they appear to be conforming. The teachers and professionals don't see the issues that are going on at home, the lack of 
sleep, the outbursts, the lack of understanding. Professionals would benefit from listening to the parents and parents benefit from taking notes and documenting what is happening [27-30].

The above is a tentative outline of what may be happening for females on the autism spectrum. It is not exhaustive or complete by any means. Not all females will fit every aspect of the above descriptions.

When an autistic individual is interested, GAMMA is enabled [31] and autistic females (like the males) are motivated to do more than they might do otherwise. Utilizing interests and strengths is the best way forward in autism. Finding ways to explore the hidden curriculum of any social society is made so much easier and available when individuals can access it via their interests. When individuals on the spectrum are not interested, motivation is switched off. Working together within individual interest is the remedy for this. It is imperative professionals consider autism in girls as an option, rather than only diagnosing various mental health issues. Of course, these can co-occur, but may not be the foundational issue so much as a secondary one.

It seems that whatever one's gender if the individual is 'somewhere' on the spectrum of autism their thinking and problem-solving abilities differ from that of the typical world. However, just because one is different or arrives at an understanding by taking a different rout, this doesn't mean there isn't value in their processing or problem-solving attributes. It makes no sense to say just because they didn't do it typically, the way they did something is wrong. But, if females are losing confidence, failing to thrive, appear to have a thought disorder, are being very literal, showing signs of demand avoidance and so on, the professional should consider the wider option of an autism assessment. Autism presents in all genders across the human condition and is not only a male prerogative.

\section{REFERENCES}

[1] Kanner L. Autistic disturbances of affective contact. Nervous Child 1943; 2: 217-250.

[2] American Psychiatric Association. Diagnostic and statistical manual of mental disorders (DSM-5) 2013.

[3] Wing L. Sex ratios in early childhood autism and related conditions. Psychiatry Research 1981; 5(2): 129-137. https://doi.org/10.1016/0165-1781(81)90043-3

[4] Asperger H. Autistic psychopathy in childhood. In U. Frith (Ed.), Autism and Asperger Syndrome. Cambridge: Cambridge University Press 1992; pp. 37-92.

[5] Attwood T. The Complete Guide to Asperger's Syndrome. Philadelphia, PA: Jessica Kingsley Publishers 2007.
[6]

Carter AS, Black DO, Tewani S, Connolly CE, Kadlec MB, Tager-Flusberg $\mathrm{H}$. Sex differences in toddlers with autism spectrum disorders. J Aut Dev Dis 2007; 37(1): 86-97. https://doi.org/10.1007/s10803-006-0331-7

[7] Lawson W. Understanding and Working with the Spectrum of Autism. London: Jessica Kingsley Publishers 2001.

[8] Lawson W. The passionate mind: How individuals with autism learn. London: JKP 2011.

[9] Kranz G, Hahn A, Kaufmann U, Koblbick M, Hummer A, Ganger, et al. White matter microstructure in transsexuals and controls investigated by diffusion tensor imaging. Journal of Neuroscience 2014.

[10] WHO, 2017: http://www.who.int/genomics/gender/en/index1. $\mathrm{html}$

[11] McPartland JC, Volkmar FR. Asperger syndrome and its relationships to autism. In the neuroscience of autism spectrum disorders, edited by Buxbaum JD, Hof PR. Oxford: Elsevier Press 2013; 55-68.

https://doi.org/10.1016/B978-0-12-391924-3.00004-1

[12] Moyse R, Porter J. The experience of the hidden curriculum for autistic girls at mainstream primary schools. European $\mathrm{J}$ of Spec Needs Edu 2015; 30(2): 187- 201. ISSN 0885-6257

[13] Cridland EK, Jones SC, Caputi P, Magee C. Being a girl in a boys' world: Investigating the experiences of girls with autism spectrum disorders during adolescence. $\mathrm{J}$ of Aut and Dev Dis 2014; 44(6): 1261-1274. https://doi.org/10.1007/s10803-013-1985-6

[14] Dean M, Kasari C, Shih W, Frankel F, Whitney R, Landa RC et al. The peer relationships of girls with ASD at school: Comparison to boys and girls with and without ASD. The Journal of Child Psychiatry and Psychology 2014.

[15] Dworzynski K, Ronald A, Bolton P, Happé F. How different are girls and boys above and below the diagnostic threshold for autism spectrum disorders? J Am Acad Child Adolesc Psychiatry 2012; 51(8): 788-97.

https://doi.org/10.1016/j.jaac.2012.05.018

[16] Harrop C, Shire S, Gulsrud A, Chang YC, Ishijima E, Lawton $\mathrm{K}$, et al. Does gender influence core deficits in ASD? An investigation into social-communication and play of girls and boys with ASD. J of Dev Dis 2015; 45(3): 766-77. https://doi.org/10.1007/s10803-014-2234-3

[17] Head AM, McGillivray JM, Stokes MA. Gender differences in emotionality and sociability in children with autism spectrum disorders Mol Autism 2014; 5: 19. Published online 2014 Feb 28 https://doi.org/10.1186/2040-2392-5-19

[18] Nichols S, Moravcik GM, Tetenbaum SP. Girls growing up on the autism spectrum: What parents and professionals should know about the pre-teen and teenage years, London: JKP 2008.

[19] Van Wijngaarden-Cremers PJ, van Eeten E, Groen WB, Van Deurzen PA, Oosterling IJ, Van der Gaag RJ. Gender, and age differences in the core triad of impairments in autism spectrum disorders: a systematic review and meta-analysis. $\mathrm{J}$ of Aut and Dev Dis 2014; 44(3): 627-35. https://doi.org/10.1007/s10803-013-1913-9

[20] Wing L, Gould J, Gillberg C. Autism spectrum disorders in the DSM-V: Better or worse than the DSM-IV? Research in Developmental Disabilities 2011; 32: 768-773.

https://doi.org/10.1016/j.ridd.2010.11.003

[21] American Psychiatric Association. Diagnostic and statistical manual of mental disorders ( $4^{\text {th }}$ Rev. ed.). Washington, DC: Author 2000.

[22] Baron-Cohen S. The extreme male brain theory of autism. Cog Sci 2002; 6(6): 248-254. https://doi.org/10.1016/S1364-6613(02)01904-6

[23] Lai M-C, Lombardo MV, Suckling J, Ruigrok ANV, Chakrabarti B, Ecker C, et al. Biological sex affects the neurobiology of autism. Brain 2013. https://doi.org/10.1093/brain/awt216 
[24] Bjorne P. Personal Communication 2017.

[25] Marshall T. Aspien Girl: The unique characteristics, traits and gifts of girls on the autism spectrum. Tania Marshal: Australia 2014.

[26] Yaull-Smith D. Gils on the spectrum: file:///C:/Users/Home/ Downloads/Dale-Yaull-Smith-Communication-29. Spring2008.pdf

[27] Myles BS. The cycle of tantrums, rage, and meltdowns in children and youth with Asperger syndrome, high-functioning autism, and related disabilities. http://www.isec2005.org.uk/ isec/abstracts/papers_m/myles_b.shtml

[28] Halladay AK, Bishop S, Constantino JN, Daniels AM, Koenig $\mathrm{K}$, Palmer $\mathrm{K}$, et al. Sex and gender differences in autism spectrum disorder: summarizing evidence gaps and identifying emerging areas of priority. Mol Autism 2015; 6: 36. PubMed. https://doi.org/10.1186/s13229-015-0019-y

[29] Constantino, John N. et al. Gender bias, female resilience, and the sex ratio in autism. J American Acad. of Child \& Adol Psych 2012; 51(8): 756-758.

https://doi.org/10.1016/j.jaac.2012.05.017

[30] Cornish MTC, Rinehart N. Does Gender Matter? A one year follow-up of autistic, attention and anxiety symptoms in high- functioning children with autism spectrum disorder. J of Aut and Develop Dis 2014; 44(5): 1077-1086. https://doi.org/10.1007/s10803-013-1964-y

[31] Lawson W. Autism spectrum conditions: The pathophysiological basis for inattention and the new Diagnostic and Statistical Manual of Mental Disorders. OA Autism 2013; 1(1): 1-5.

https://doi.org/10.13172/2052-7810-1-1-343

\section{HELPFUL WEB SITES}

https://taniaannmarshall.wordpress.com/2013/03/26/moving-towardsa-female-profile-the-unique-characteristics-abilities-and-talents-ofasperwomen-adult-women-with-asperger-syndrome/

https://www.amazon.com/Am-Aspiengirl-Characteristics-FemalesSpectrum/dp/0992360900

https://www.scientificamerican.com/article/autism-it-s-different-ingirls/

https://iancommunity.org/ssc/girls-autism-hiding-plain-sight

https://www.youtube.com/watch?v=oZhZ0k1lyF8

https://www.youtube.com/watch?v=i4zMelZfU-s

https://www.youtube.com/watch?v=IvhiW7ilTDk

Received on 26-08-2017

Accepted on 20-09-2017

Published on 17-10-2017

DOI: https://doi.org/10.6000/2292-2598.2017.05.03.4

(C) 2017 Wenn B. Lawson; Licensee Lifescience Global.

This is an open access article licensed under the terms of the Creative Commons Attribution Non-Commercial License (http://creativecommons.org/licenses/by-nc/3.0/) which permits unrestricted, non-commercial use, distribution and reproduction in any medium, provided the work is properly cited. 